\title{
HIGH-TEMPERATURE OXIDATION OF CHROME-NICKEL ALLOY
}

\author{
Adéla Chalupováa, ${ }^{a, c}$, Martin SteinbrücK $^{b}$, Mirco Grosse $^{b}$, \\ JAKUB KRejČ́i ${ }^{c}$, MARTin ŠEveČEK ${ }^{a}$ \\ ${ }^{a}$ Czech Technical University in Prague, Faculty of Nuclear Sciences and Physical Engineering, Department of \\ Nuclear Reactors, V Holešovickách 2, 18000 Prague 8, Czech Republic \\ ${ }^{b}$ Karlsruhe Institute of Technology, Hermann-von-Helmholtz-Platz 1, 76344 Eggenstein-Leopoldshafen, \\ Germany \\ ${ }^{c}$ UJP PRAHA a.s., Nad Kaminkou 1345, Praha-Zbraslav, 15610, Czech Republic \\ * corresponding author: chalupova@ujp.cz
}

Abstract.

The investigations in this paper deal with the $\mathrm{Cr}-\mathrm{Ni}$ alloy. The material has been recently proposed as a potential ATF concept, primarily due to its behaviour under high-temperature oxidation. A set of experiments to determine the melting point and describe the oxidation kinetics of the $\mathrm{Cr}-\mathrm{Ni}$ alloy were performed in Karlsruhe Institute of Technology. Presented results reveal its superb oxidation resistance comparing to zirconium alloys. Therefore, the alloy has a great potential for nuclear applications.

KeYwords: ATF, Cr-Ni, fuel cladding, high-temperature oxidation, LOCA, nuclear fuel.

\section{INTRODUCTION}

Zr-based cladding has been used in light water reactors for many decades. It has been chosen for nuclear applications due to its low thermal neutron capture cross-section together with good corrosion behaviour under normal operation conditions. Yet, in high-temperature steam, such as might occur under severe accident conditions, a rapid increase in oxidation kinetics is observed. In response to the events in Three Mile Island (1979) and more recently in Fukushima Dai-ichi (2011), the development and deployment of advanced accident tolerant fuel (ATF) became of worldwide interest [1].

One of the possible approaches to achieve higher safety during severe accident scenarios is to replace the current zirconium alloys with new materials with higher oxidation resistance and lower heat and hydrogen production. An alloy similar to $42 \mathrm{XHM}$ is considered as a promising material in the development of ATF. The 42XHM alloy is highly resistant to water vapour and it almost does not undergo to low-temperature embrittlement. The alloy has been already used as the structural material of absorbing rods in WWER-1000 reactors and as the fuel cladding in nuclear-powered ships and submarines. The previous experiments on $42 \mathrm{XHM}$ alloy were presented in [2], [3].

Nevertheless, in comparison to the Zr-based cladding, the $\mathrm{Cr}-\mathrm{Ni}$ has a large thermal neutron absorption cross-section. Several solutions to counterbalance the absorption have been proposed. The strength of the alloy allows thinner cladding; hence the pellets can be slightly larger to give the same cold gap width in the rod. Still, even with a thinner cladding wall, it appears necessary to increase the fuel enrichment beyond the current $5 \%$ limit. Another way to compensate for the high thermal neutron absorption is the implementation of high-density fuel instead of $\mathrm{UO}_{2}$ ceramics. To increase the capacity of uranium, it has been proposed to use heavily doped uranium-molybdenum fuel as well as modified uranium silicide fuel or a dispersion type fuel [4].

The melting point and high-temperature oxidation of the $\mathrm{Cr}-\mathrm{Ni}$ alloy were studied and the results are presented.

\section{Methods}

\subsection{MATERIAL}

The chemical composition of the Cr-Ni alloy used for these experiments is summarized in Table 1. Segments were cut from non-irradiated longer tubes, deburred, ground, and cleaned in acetone. The ultrasonically cleaned specimen was measured using an analytical balance with a resolution of $0.0001 \mathrm{~g}$ and a calliper with a resolution of $0.01 \mathrm{~mm}$. As the deformation is not isotropic, the length was measured at 3 locations of the specimen and the final length is the average of these three measurements. The geometry of the tested specimens was cylindrical with a height of $20 \mathrm{~mm}$, an outer diameter of $8.3 \mathrm{~mm}$, and an inner diameter of $7.1 \mathrm{~mm}$. Before each experiment, the specimen was weighed in a balance with a resolution of $0.1 \mathrm{mg}$ to determine the mass gain during the exposition and to compare it with data obtained from TG. 


\begin{tabular}{lllll}
\hline Element & $\mathrm{Cr}$ & $\mathrm{Mo}$ & $\mathrm{Ti}$ & $\mathrm{Ni}$ \\
\hline wt.\% & 42 & $1-1.5$ & 0.25 & Balance \\
\hline
\end{tabular}

TABle 1. Chemical composition of Cr-Ni alloy

\subsection{Differential thermal analysis}

Differential thermal analysis (DTA) is a thermoanalytic technique to analyse a change in properties of a sample, i.e., melting, decomposition, or changes in the crystal structure. In DTA, the temperature of a sample is compared with the reference material. The reactions are typically graphed from an arbitrary baseline as a function of temperature. Exothermic reactions per definition show upward curves and endothermic reactions downward curves from the baseline. The DTA analysis was performed to determine the accurate melting point of the $\mathrm{Cr}-\mathrm{Ni}$ alloy.

Thermal balance, particularly a simultaneous thermal analysis facility, STA 449 F3 Jupiter Eco from NETZCH company, allowing the measurement of mass changes and thermal effects, was used to perform the differential thermal analysis. Contrary to most STAs, the balance does not use the external thermostat and the temperature of the chamber is regulated electronically.

The sample of $\mathrm{Cr}-\mathrm{Ni}$ alloy and the reference alumina powder $\left(\mathrm{Al}_{2} \mathrm{O}_{3}\right)$ were weighted and placed symmetrically in the STA facility. The furnace was programmed to heat up to $1450^{\circ} \mathrm{C}(30 \mathrm{~K} / \mathrm{min})$ and subsequently to cool down to $100^{\circ} \mathrm{C}(100 \mathrm{~K} / \mathrm{min})$. During the process, a differential thermocouple was set to detect the temperature difference between the sample and the reference powder. The experiment was carried out in argon atmosphere to prevent oxidation reactions.

\subsection{ThERMO-GRAVIMETRIC EXPERIMENT}

The most common method of measuring oxidation rate is the observation of oxide accumulation in time. The gravimetric measurements in this study were performed continuously. The experimental facility consisted of a thermal balance STA 449 F3 Jupiter from NETZSCH company, the steam generator from Bronkhorst Company, and a quadrupole mass spectrometer NETZSCH QMS 403 C. The facility STA 449 F3 Jupiter presents the older configuration compared to the STA mentioned before. The weighting chamber's temperature is regulated by an external thermostat.

The measured specimen was placed into the furnace. An alumina plate was used to support the specimen, as shown in Figure 1. First, the furnace was sealed and purged with argon for 10 minutes to remove the atmospheric gases. All experiments were performed with a flow rate of pure steam of $2 \mathrm{~g} / \mathrm{h}$. Additionally, $50 \mathrm{ml} / \mathrm{min}$ of argon was injected in the balance volume as a protective and carrier gas. Considering the given flow rates and the molar volume

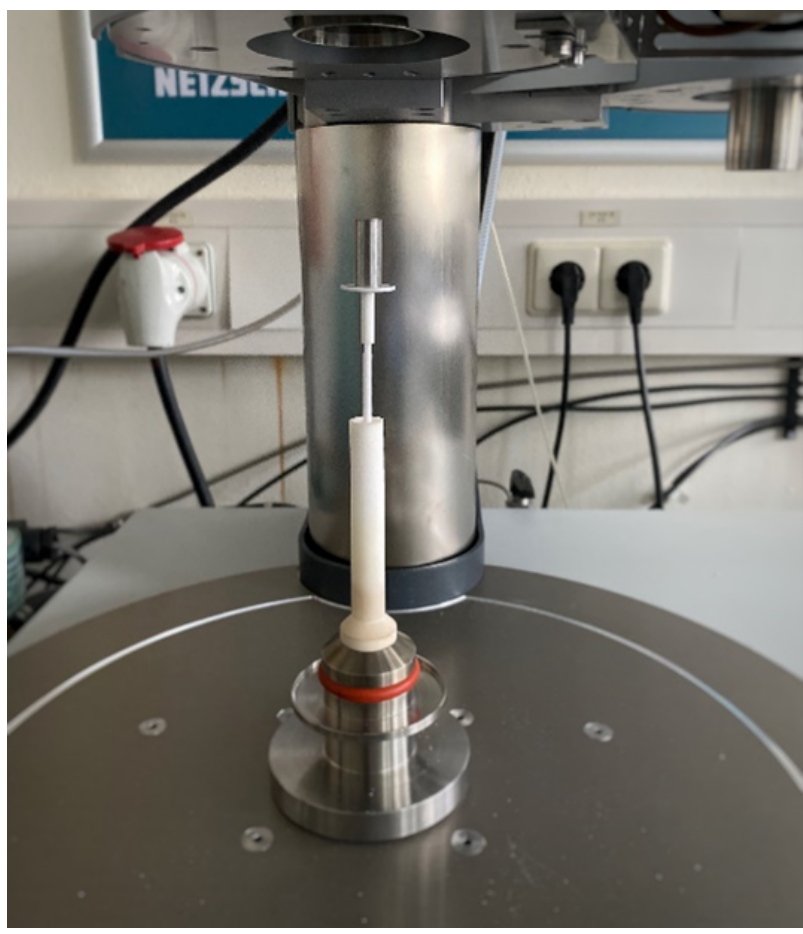

FiguRE 1. Specimen before exposition under high temperature steam oxidation



FiguRE 2. Isothermal experiment

of argon $22.4 \mathrm{dm}^{3}$, the resulting steam molar concentration in the fluid at the outlet was $45 \%$. Due to the special construction of the furnace, the steam concentration of the sample was over $95 \%$. Oxidation occurred on both sides. Generally, two varieties of the experiment were performed - isothermal tests with 20 hours annealing time and a transient test with a heating rate of $5-10{ }^{\circ} \mathrm{C} / \mathrm{min}$.

To determine the oxidation kinetics of the $\mathrm{Cr}-\mathrm{Ni}$ alloy, a set of isothermal experiments was performed. The course of an experiment is shown in Figure 2. The test was initiated at a temperature of $90^{\circ} \mathrm{C}$. The specimen was subsequently heated up to the desired temperature with a heating rate of $10 \mathrm{~K} / \mathrm{min}$. The 10-minute long isothermal phase followed to homogenize the temperature and to adjust the vapour generation. The subsequent temperature plateau with vapour supply took 20 hours. Finally, the specimen 


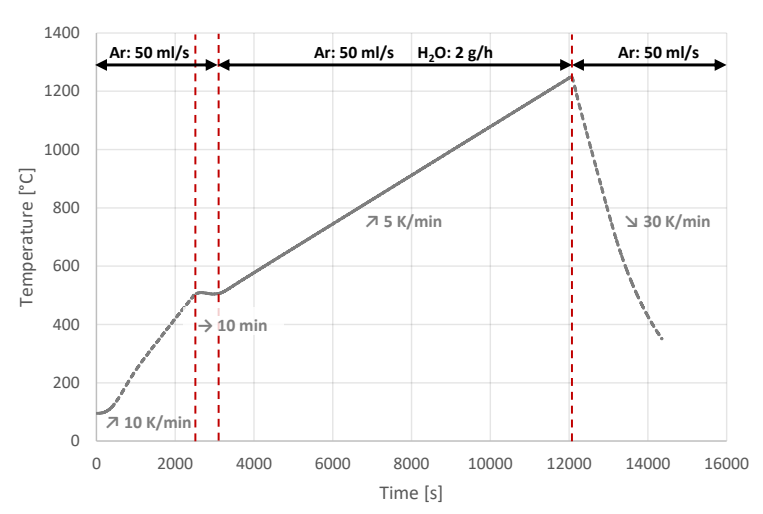

Figure 3. The transient experiment

was cooled down to $100{ }^{\circ} \mathrm{C}$ with the cooling rate of 5 $\mathrm{K} / \mathrm{min}$. The isothermal experiments were performed at the temperatures of $700{ }^{\circ} \mathrm{C}, 800{ }^{\circ} \mathrm{C}, 900{ }^{\circ} \mathrm{C}, 1000$ ${ }^{\circ} \mathrm{C}, 1100{ }^{\circ} \mathrm{C}$ and $1200{ }^{\circ} \mathrm{C}$.

To confirm the change in kinetics, the transient experiment was performed. The course of the experiment is summarized in Figure 3. The test was initiated at $90{ }^{\circ} \mathrm{C}$. Subsequently, the specimen was heated with the heating rate of $10 \mathrm{~K} / \mathrm{min}$ up to 500 ${ }^{\circ} \mathrm{C}$. The isothermal period at the temperature of 500 ${ }^{\circ} \mathrm{C}$ followed for 10 minutes. Afterwards, the constant steam flow of $2 \mathrm{~g} / \mathrm{h}$ was initiated, and the specimen continued to heat up to $1240{ }^{\circ} \mathrm{C}$ with the heating rate of $5 \mathrm{~K} / \mathrm{min}$. Finally, the specimen was cooled down to the temperature of $100{ }^{\circ} \mathrm{C}$ with the cooling rate of $30 \mathrm{~K} / \mathrm{min}$ in argon.

\subsection{Post-test examination}

The thermogravimetric analysis and mass spectroscopy were measured online during the experiment. Eventually, the obtained data were analysed and the expected corrosion rate was calculated based on the specific oxidation behaviour, by means of parabolic or linear kinetics.

The specimens were visually analysed to detect any relevant changes in appearance, i.e., the colour of the oxide, macroscopic dissolution, cracking, or spalling.

To perform further analysis, it was necessary to cut the specimens into several rings. The metallographic cross-sections were prepared using the standard polishing procedure and metallographic evaluation followed. The thickness of the oxide scale and the wall were measured. Additionally, the specimen's surface was treated with Au before scanning electron microscopy (SEM) analysis.

A SEM is an electron microscopy technique that produces images of a sample by scanning the surface with a focused beam of electrons. The electrons interact with atoms in the sample, producing various signals that contain information about the surface topography and composition of the sample. The received signals are collected and examined. Specific Xray energies or wavelengths are selected and counted

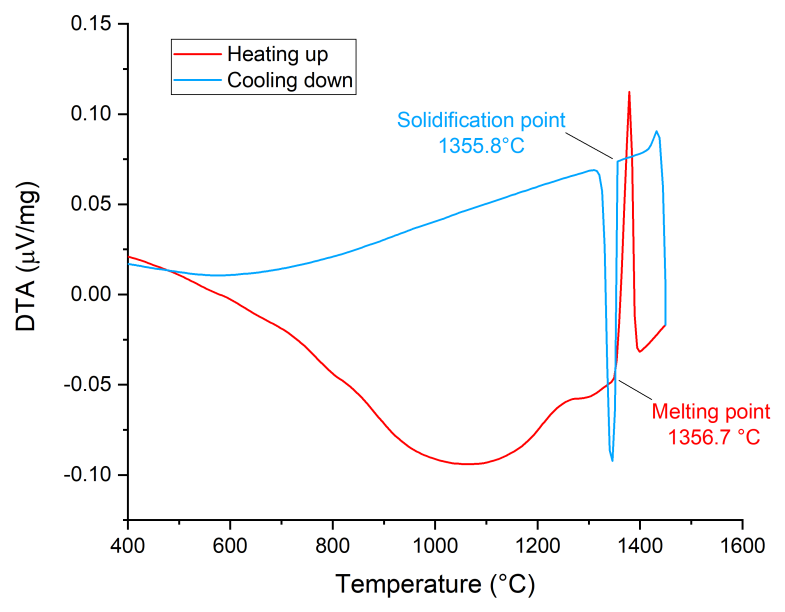

Figure 4. The determined melting point and the solidification point of $\mathrm{Cr}-\mathrm{Ni}$ alloy

via energy-dispersive X-ray spectroscopy (EDS) for elemental analyses.

The surface and under-surface morphologies of Cr$\mathrm{Ni}$ alloy after oxidation at $1200{ }^{\circ} \mathrm{C}$ in steam for 20 hours were analysed using SEM/EDS. Chemical elements present in the specimen were determined qualitatively.

\section{Results}

\subsection{The Melting Point Determination}

During DTA, the transition temperatures were determined. The DTA graph in Figure 4 visualizes DTA in relation to temperature. The nature of the reaction was derived from the peak orientation. The melting causes an endothermic reaction, the onset of the signal was determined at $1356.7^{\circ} \mathrm{C}$. The solidification causes an exothermic reaction. According to the graph, it was initiated at a lower temperature of $1355.8^{\circ} \mathrm{C}$.

\subsection{High-TEMPERATURE OXIDATION}

During oxidation, the water molecules are adsorbed on the surface of the metal, they dissociate, and the oxygen diffuses into the metal. After reaching the solubility limit of oxygen in the metal, the oxide scale is formed and thickens at the expense of the metal. Generally, the rate of thickening determines the oxidation kinetics [5] [6].

The kinetics of oxidation can be described by equation (1).

$$
\frac{W G}{S}=k_{m} \cdot t^{n}
$$

where WG is the weight gain of the specimen, $\mathrm{S}$ is the surface of the sample, $k_{m}$ is the rate constant, and $t$ is the oxidation time of the isothermal experiment.

The weight gain per unit area in relation to time for isothermal experiments in steam at various temperatures is shown in Figure 5. There are two major trends. The weight gain of the alloy under oxidation 


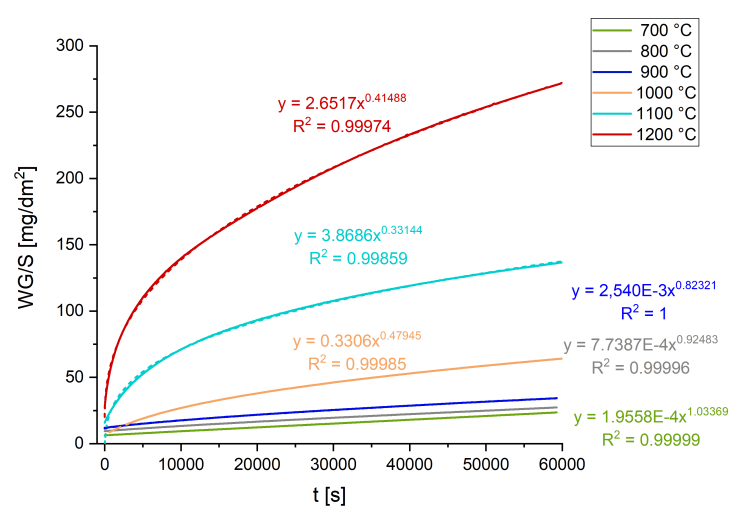

Figure 5. Oxidation kinetics of $\mathrm{Cr}-\mathrm{Ni}$ at $700{ }^{\circ} \mathrm{C}, 800$ ${ }^{\circ} \mathrm{C}, 900{ }^{\circ} \mathrm{C}, 1000{ }^{\circ} \mathrm{C}, 1100{ }^{\circ} \mathrm{C}$ and $1200{ }^{\circ} \mathrm{C}$ in steam. The dot curves indicate a fitting relationship between weight gain over an area unit and oxidation time of 20 hours

\begin{tabular}{ll}
\hline Temperature $\left[{ }^{\circ} \mathbf{C}\right]$ & Time exponent $\mathbf{n}$ \\
\hline 700 & 1.03369 \\
800 & 0.92483 \\
900 & 0.82321 \\
1000 & 0.47945 \\
1100 & 0.33144 \\
1200 & 0.41488 \\
\hline
\end{tabular}

TABle 2. Time exponents of the oxidation kinetics of $\mathrm{Cr}-\mathrm{Ni}$ alloy at various temperatures

temperatures between $700{ }^{\circ} \mathrm{C}$ and $900{ }^{\circ} \mathrm{C}$ is rather linear. Above $1000{ }^{\circ} \mathrm{C}$ the curve is more likely parabolic, yet not precisely. The curves in Figure 5 show the fitting results of weight gain per unit area in relation to time. Time exponents from (1) are summarized in Table 2 for all experimental temperatures.

Figure 6 shows the hydrogen concentration in the off-gas during the isothermal experiment at $1200{ }^{\circ} \mathrm{C}$ as a function of time. Considering that the steam molar concentration in the fluid is $45 \%$, the hydrogen release rates measured by the mass spectrometer are proportional to WG/S and in good correspondence to the calculation. At the early stage of oxidation, the hydrogen release is increased due to the faster oxidation rate. The subsequent stabilization in oxidation rate can be attributed to the protective oxide scale formation.

Figure 7 presents the general posttest appearance after isothermal oxidation in steam at $700{ }^{\circ} \mathrm{C}, 800$ ${ }^{\circ} \mathrm{C}, 900{ }^{\circ} \mathrm{C}, 1000{ }^{\circ} \mathrm{C}, 1100{ }^{\circ} \mathrm{C}$ and $1200{ }^{\circ} \mathrm{C}$ for 20 hours and after oxidation at a temperature transient with the maximum temperature of, $1250{ }^{\circ} \mathrm{C}$. All specimens showed a compact structure. They differ in colour and degree of degradation. Apparently, the oxide scale changes from green monotone grey to monochrome grey with a visible pattern. Despite the compact structure of the specimens, at temperatures

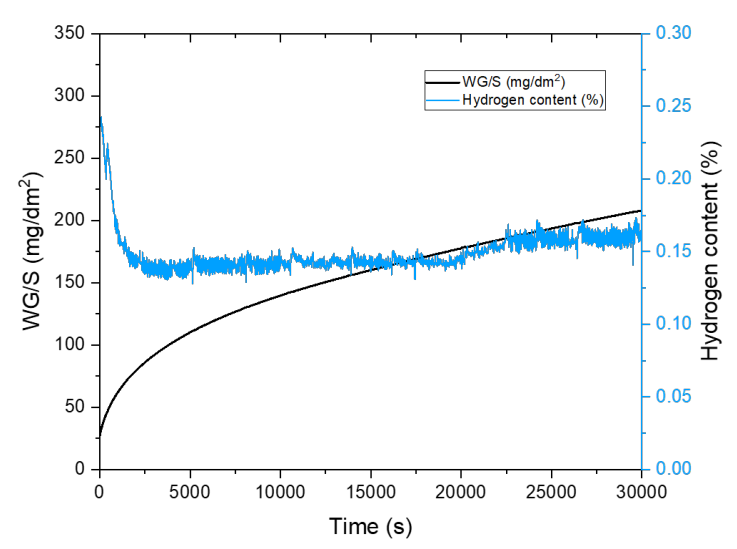

FiguRE 6. Hydrogen content in time during the isothermal experiment at the temperature of 1200 ${ }^{\circ} \mathrm{C}$



Figure 7. Post-test appearance of $\mathrm{Cr}-\mathrm{Ni}$ after oxidation at temperature transient for 150 minutes and after oxidation in steam at 6 different temperatures: $700{ }^{\circ} \mathrm{C}, 800{ }^{\circ} \mathrm{C}, 900{ }^{\circ} \mathrm{C}, 1000{ }^{\circ} \mathrm{C}, 1100{ }^{\circ} \mathrm{C}, 1200{ }^{\circ} \mathrm{C}$ for 20 hours

of $1100{ }^{\circ} \mathrm{C}$ and $1200{ }^{\circ} \mathrm{C}$, a fine powder falling from the specimens' surface to the plate crucible was observed.

The metallographic image in Figure 8 gives a closer view of the structure of the specimens. At a first glance, the specimens show discontinuous porous oxide scale. Thus, it appears unprotective. On the contrary, the oxidation kinetics remained in between parabolic and cubic $(\mathrm{n}=0.33-0.48)$ with no evidence of 


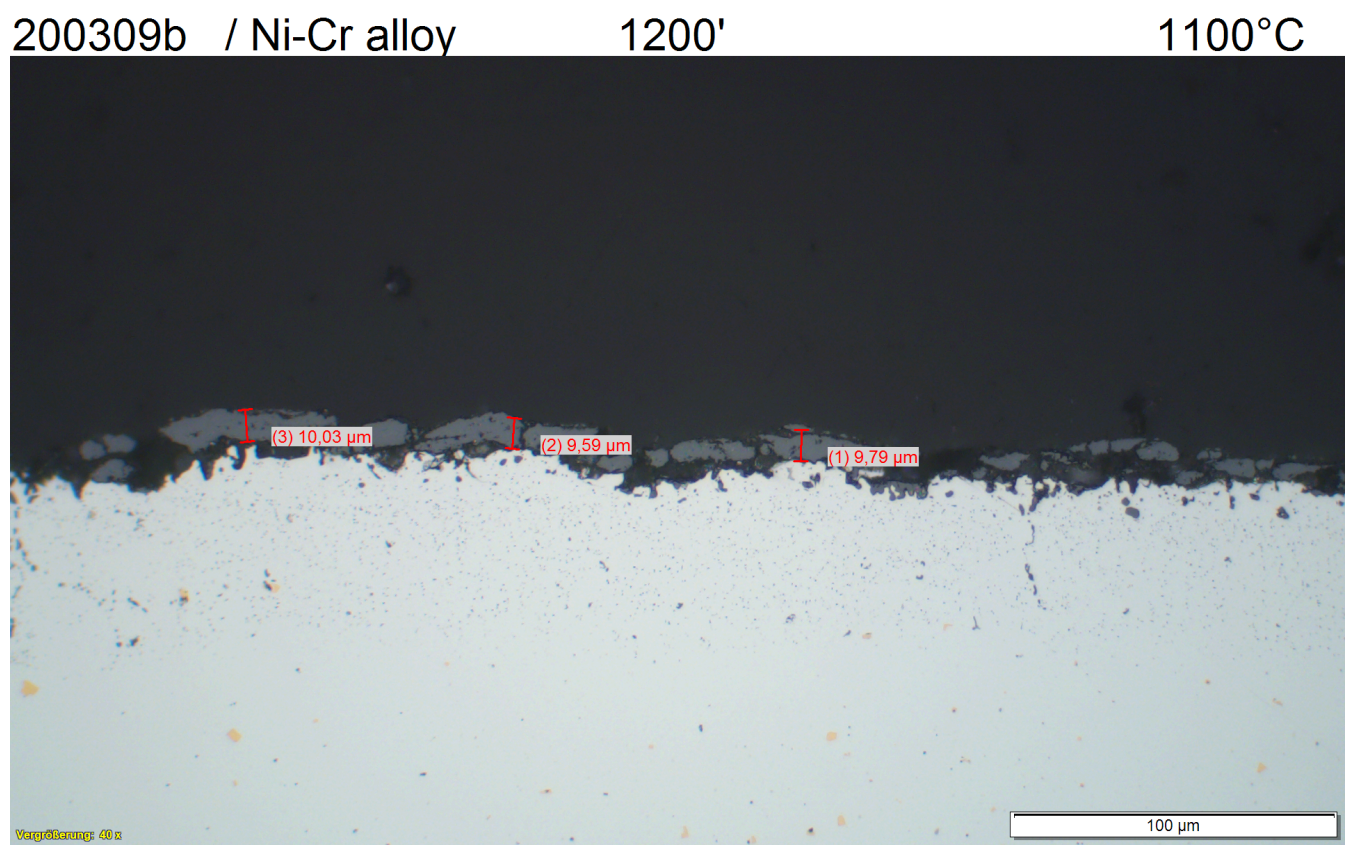

Figure 8. Microstructure of specimen cross sections after isothermal oxidation at $1100{ }^{\circ} \mathrm{C}$ in steam for 20 hours

kinetics transition. A possible explanation could be the delamination of the oxide scale during the cooldown period and breaking of the hard oxide during the metallographic preparation of the samples. This fact is supported by the presence of fine powder in the TG balance volume after the experiment.

Micrographs in Figure 9 to Figure 11 present SEM analysis of the surface and under-surface morphologies of the $\mathrm{Cr}-\mathrm{Ni}$ alloy after oxidation at $1200{ }^{\circ} \mathrm{C}$ in steam for 20 hours with corresponding EDS measurements. The SEM/EDS image in Figure 9 identified the discontinuous surface layer of $\mathrm{Cr}_{2} \mathrm{O}_{3}$. The carbon and $\mathrm{Au}$ impurities are detected due to the polishing procedure and surface treatment before SEM/EDS. EDS mapping in Figure 10 shows Ni-Cr morphology in the specimen's wall. Isolated Ti-enriched islands were occasionally observed by EDS, as shown in Figure 11 .

\section{Discussion}

The melting point of the Cr-Ni alloy was determined using the differential thermal analysis to $1356.6{ }^{\circ} \mathrm{C}$. According to the Ni-Cr phase diagram [7], the melting point of nickel and chromium at the pressure of $101325 \mathrm{~Pa}$ is $1390{ }^{\circ} \mathrm{C}$, regarding the content of chromium $42 \%$. The phase transformation of the real alloy is influenced by the heating rate and its composition. In comparison, the melting point of zirconium alloy reaches $1850{ }^{\circ} \mathrm{C}$. However, since the exothermic oxidation rate of $\mathrm{Ni}-\mathrm{Cr}$ alloy is far more moderate than in the case of zirconium cladding, the melting temperature is expected to be reached later in a typical accident scenario, hence the coping time is increased. Consequently, the lower melting point may not be a limiting factor for ATF requirements.

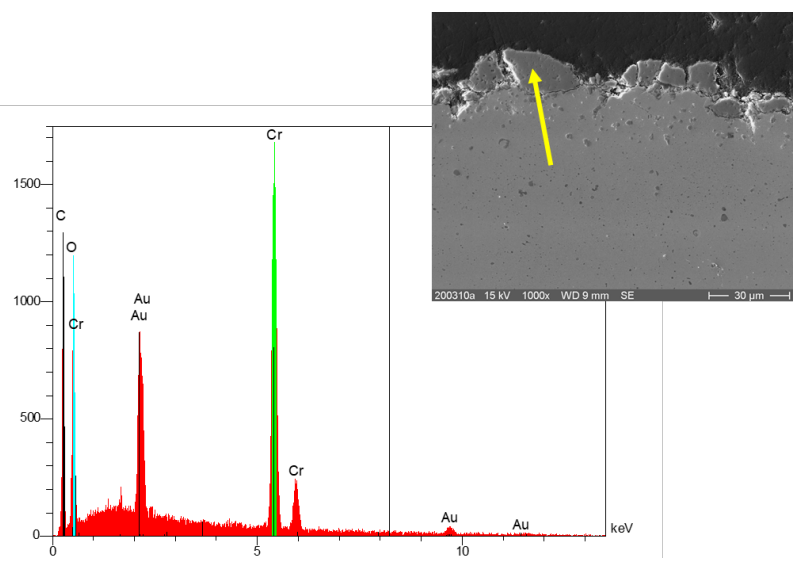

FiguRE 9. SEM micrograph of oxide scale formed on the surface of $\mathrm{Cr}-\mathrm{Ni}$ after oxidation at $1200{ }^{\circ} \mathrm{C}$ in steam for 20 hours accompanied with EDS measurement of the marked point

The oxidation kinetics of the Cr-Ni alloy were studied in the temperature range from $700{ }^{\circ} \mathrm{C}$ up to 1200 ${ }^{\circ} \mathrm{C}$. The alloy exhibited rather linear kinetics after oxidation in steam at temperatures $700{ }^{\circ} \mathrm{C}$ and 800 ${ }^{\circ} \mathrm{C}$. At temperatures from $900{ }^{\circ} \mathrm{C}$ to $1200{ }^{\circ} \mathrm{C}$ the oxidation rate of the alloy starts to be controlled by diffusion and thus it resembles the parabolic kinetics. It was confirmed that the $\mathrm{Cr}-\mathrm{Ni}$ has very low weight gain, i.e., WG/S from equation (1), under high-temperature oxidation. In view of this fact, a very high precision of the experiment is desirable.

Figure 12 shows the Arrhenius plot for various proposed ATF designs (Cr-Ni. FeCrAl, Inconel 617) in comparison to standard Zr-based cladding materials (Zr1\%Nb, Zircaloy-4) and Cathcard-Pawel correlation. On the whole, all potential ATF materials outperform Zr-based alloys. It needs to be mentioned 


\begin{tabular}{lll}
\hline Temperature range $\left[{ }^{\circ} \mathbf{C}\right]$ & $\mathbf{A}\left[\mathrm{mg} \cdot \mathrm{dm}^{-2} \cdot \mathrm{s}^{1 / 2}\right]$ & $\mathrm{B}[\mathrm{K}]$ \\
\hline $700-900$ & 0.2 & -6951.9 \\
$1000-1200$ & 3339.8 & -15468.0 \\
\hline
\end{tabular}

TABlE 3. Calculated parameters A and B from Arrhenius equation for oxidation kinetics of Cr-Ni alloy

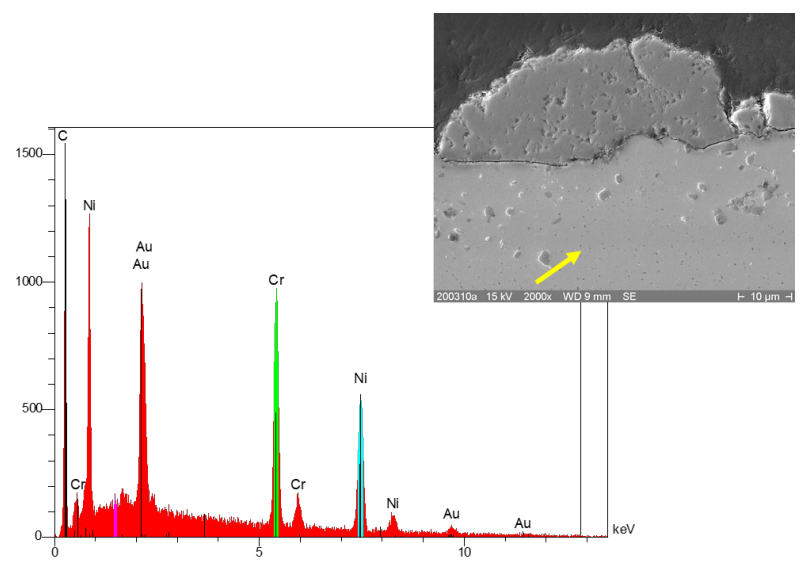

FIGURE 10. SEM micrograph of the wall beneath the oxide scale of $\mathrm{Cr}-\mathrm{Ni}$ after oxidation at $1200{ }^{\circ} \mathrm{C}$ in steam for 20 hours accompanied with EDS measurement of the marked point

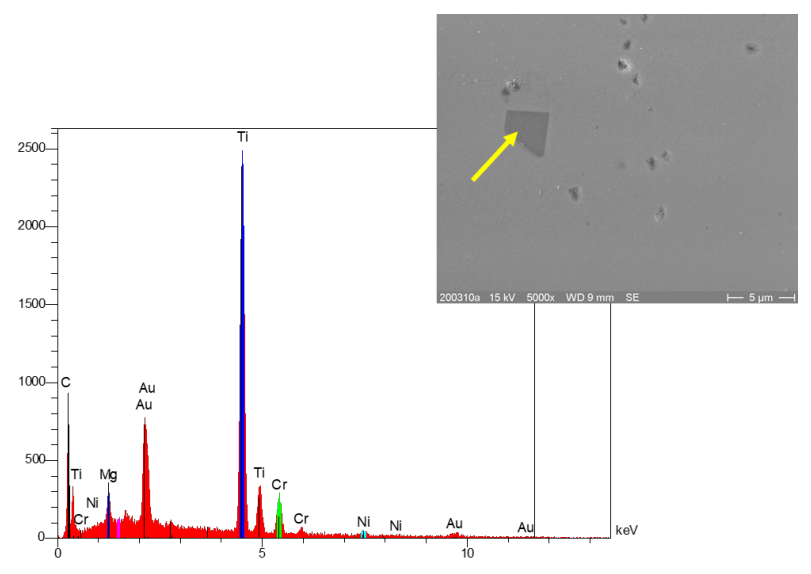

FiguRE 11. SEM micrograph of the Ti grain formed beneath the oxide scale of $\mathrm{Cr}-\mathrm{Ni}$ after oxidation at $1200{ }^{\circ} \mathrm{C}$ in steam for 20 hours accompanied with EDS measurement of the marked point

that the correlation for $\mathrm{Cr}-\mathrm{Ni}$ alloy is not highly accurate, given that its kinetics does not correspond to the parabolic law, see Table 2 .

To determine the activation energy from experiments at isothermal temperatures, the Arrhenius equation (2) has been used.

$$
k=A \cdot e^{\frac{E}{R \cdot T}}=A \cdot e^{-\frac{B}{t}}
$$

where $\mathrm{k}$ is the rate constant, $\mathrm{A}$ is the frequency factor or preexponential factor, $\mathrm{E}$ is the activation energy for the reaction, $\mathrm{R}$ is the gas constant, and $\mathrm{T}$ is the absolute temperature. Therefore, the oxidation rate is a function of reaction temperature and examined material.

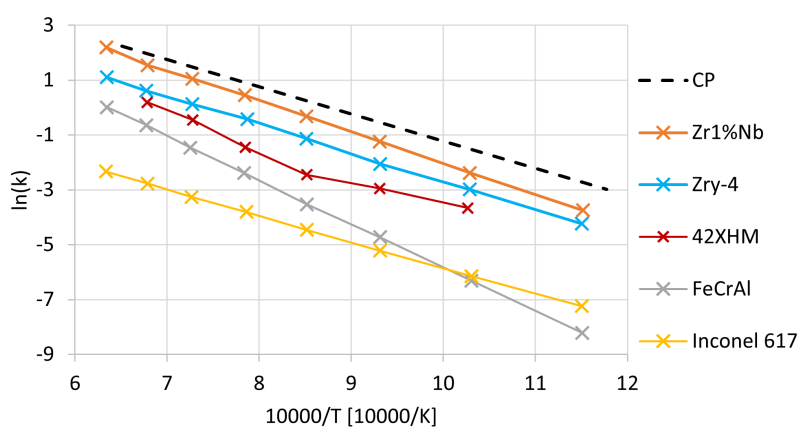

Figure 12. Arrhenius-plot of the estimated oxidation rate constants for various alloys, i.e. $\mathrm{Zr} 1 \% \mathrm{Nb}$, Zircaloy-4, Cr-Ni, FeCrAl in steam [8]

The parameters A and B were estimated considering parabolic kinetics. Results are summarized for two temperature ranges in Table 3 .

\section{Conclusions}

The presented results show a better resistance of Cr$\mathrm{Ni}$ alloy compared to zirconium alloys during hightemperature oxidation in steam. All visual evaluation, microstructure analysis, and weight gain, together with the derived oxidation kinetics parameters confirmed its stability under severe accident conditions. These conclusions confirm that $\mathrm{Cr}-\mathrm{Ni}$ is a promising ATF material candidate.

The main disadvantage of the the alloy is the high cross-section of thermal neutrons. Accordingly, a few possible ideas on how to improve the alloy's neutron performance were introduced. It has been declared that the $\mathrm{Cr}-\mathrm{Ni}$ alloy (42XHM) allows a thinner wall of the cladding compared to zirconium. However, sufficient compensation for the high thermal neutron absorption requires a substantial increase in fuel enrichment [4]. The alloy is often associated with fourth-generation reactors. An implementation of high-density fuel instead of uranium dioxide pellets increases the capacity of uranium, hence the usage of the oxidation-resistant $\mathrm{Cr}-\mathrm{Ni}$ alloy as a cladding material could be a possible way to achieve a highly efficient and essentially safe fuel system.

\section{ACKNOWLEDGEMENTS}

The authors thank the whole group of High-temperature Materials Chemistry (namely: P. Severoloh, Ulrike Stegmaier, Jürgen Moch) for sample preparation and posttest evaluation.

This research was held during the internship, financially supported through the ENEN+ project, that has 
received funding from the Euratom research and training Work Programme 2016 - 2017 - 1 \#755576.

\section{REFERENCES}

[1] K. A. Terrani. Accident tolerant fuel cladding development: Promise, status, and challenges. Journal of Nuclear Materials 501, 2018.

DOI:10.1016/j.jnucmat.2017.12.043.

[2] A. V. Vatulin, V. P. Kondrat'ev, V. N. Rechitskii, M. I. Solonin. Corrosion and radiation resistance of "bochvaloy" nickel-chromium alloy 46(11):469-473. Number: 11 Reporter: Metal Science and Heat Treatment, DOI:10.1007/s11041-005-0004-8.

[3] B. Gurovich, A. Frolov, I. Fedotov. Improved evaluation of ring tensile test ductility applied to neutron irradiated $42 \mathrm{xnm}$ tubes in the temperature range of $(500-1100)^{\circ} \mathrm{c}$. Nuclear Engineering and Technology 52(6):1213 - 1221, 2020. DOI:10.1016/j.net.2019.11.019.

[4] A. A. Savchenko, M. Leontieva-Smirnova, G. Kulakov, et al. Peculiarities of stainless steel application as atf in vver's. 2018.
[5] D. J. Young. Chapter 1 - the nature of high temperature oxidation. In D. J. Young (ed.), High Temperature Oxidation and Corrosion of Metals (Second Edition), pp. 1 - 30. Elsevier, second edition edn., 2016. DOI:10.1016/B978-0-08-100101-1.00001-7.

[6] D. J. Young. Chapter 3 - oxidation of pure metals. In D. J. Young (ed.), High Temperature Oxidation and Corrosion of Metals (Second Edition), pp. 85 - 144. Elsevier, second edition edn., 2016.

DOI:10.1016/B978-0-08-100101-1.00003-0.

[7] C. T. Inc. Nickel-Chromium (Ni-Cr) Phase Diagram. http://www. calphad.com/nickel-chromium.html.

[8] M. Steinbrück, N. Vér, M. Große. Oxidation of advanced zirconium cladding alloys in steam at temperatures in the range of $600-1200{ }^{\circ} \mathrm{c}$. Oxidation of Metals 76:215-232, 2011. 